\title{
DÜBLIN
}

Technological University Dublin

ARROW@TU Dublin

\section{A Study of Antiferroelectric Liquid Crystals Using the Pyroelectric Technique}

\author{
J.W. O'Sullivan \\ Trinity College Dublin, Ireland \\ Yuri Panarin \\ Technological University Dublin, yuri.panarin@tudublin.ie \\ J.K. Vij \\ Trinity College Dublin, Ireland
}

See next page for additional authors

Follow this and additional works at: https://arrow.tudublin.ie/engscheleart2

Part of the Electrical and Computer Engineering Commons

\section{Recommended Citation \\ O'Sullivan, J. et al. (1997). A study of antiferoelectric liquid crystals using the pyroelectric technique. Molecular Crystals and Liquid Crystals, vol. 301, pg. 189-194.}

This Article is brought to you for free and open access by the School of Electrical and Electronic Engineering at ARROW@TU Dublin. It has been accepted for inclusion in Articles by an authorized administrator of ARROW@TU Dublin. For more information, please contact arrow.admin@tudublin.ie, aisling.coyne@tudublin.ie, gerard.connolly@tudublin.ie.

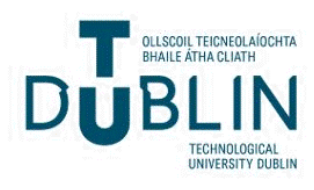




\section{Authors}

J.W. O'Sullivan, Yuri Panarin, J.K. Vij, A.J. Seed, M. Hird, and J.W. Goodby

This article is available at ARROW@TU Dublin: https://arrow.tudublin.ie/engscheleart2/147 
Mol. Cryst. Liq. Cryst., 1997, Vol. 301, pp. 189-194

Reprints available directly from the publisher

Photocopying permitted by license only
O 1997 OPA (Overseas Publishers Association)

Amsterdam B.V. Published in The Netherlands under license by Gordon and Breach Science Publishers Printed in India

\title{
A STUDY OF ANTIFERROELECTRIC LIQUID CRYSTALS USING THE PYROELECTRIC TECHNIQUE
}

\section{J. W. O' SULLIVAN, Yu. P. PANARIN, J. K. VIJ*}

Department of Electronic and Electrical Engineering, University of Dublin, Trinity College, Dublin 2, Ireland.

\section{A. J. SEED, M. HIRD and J. W. GOODBY}

School of Chemistry, University of Hull, Cottingham Road, Hull, HU6 7RX, U.K.

\begin{abstract}
Antiferroelectric liquid crystals are studied using the pyroelectric technique. The effects of temperature and applied voltage on the pyroelectric signal are examined. The pyroelectric signal can detect phase changes that occur due to temperature and bias voltage. A high temperature ferrielectric phase FiLC is found and the stability of this phase under different bias voltages is examined.
\end{abstract}

\section{INTRODUCTION}

The occurrence of anti-ferroelectricity in some chiral liquid crystals ${ }^{1}$ has regenerated enormous interest both in liquid crystal research ${ }^{2-5}$ and in industrial applications 6 . Pyroelectricity is an intrinsic property of Ferroelectric Liquid Crystals (FLC) and has been investigated previously by a number of research groups 7,8 . In this paper we study the pyroelectric properties that occur in AFLC's. The sample to be investigated in this paper is AFLC (AS-573) synthesised at Hull with the formula given as follows:

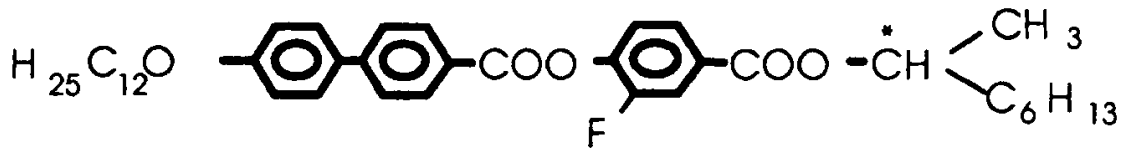

This sample exhibits ferro-, ferri- and antiferroelectric phases with transitions as defined by spontaneous polarization measurements as follows: SmA $93^{\circ} \mathrm{C} \mathrm{SmC*} 89^{\circ} \mathrm{C}$ FiLC(?) $8^{\circ} \mathrm{C} \mathrm{AF} 83^{\circ} \mathrm{C} \mathrm{SmC \gamma} 78^{\circ} \mathrm{C} \mathrm{SmC}$. The existence of these phases is predicted by the Ising model which takes into consideration competition between the Ferroelectric $(F)$ and Antiferroelectric (A) ordering. The Ising model produces a temperature induced Devil's staircase which predicts the possible phases which may exist with increasing temperature. Any structure on the staircase can be defined by a parameter $\mathrm{q}_{\mathrm{T}}$, which

*author for correspondence 
denotes the fraction of ferroelectric ordering in a periodic structure, $q_{T}=F /(A+F)$. Here $F$ is the number of ferroelectric ordering and $A$ is the number of antiferroelectric ordering in a periodic structure with a period defined by $A+F$. The Ising model can also predict the electric field induced staircase, described by structure parameter $\mathrm{q}_{\mathrm{E}}$, where $\mathrm{q}_{\mathrm{E}}=$ $R /(R+L)$, and $R$ and $L$ are the number of right and left tiling molecules. Thus we examine the pyroelectric properties of an AFLC to find the phases that are predicted by the Ising model on the temperature and field induced staircases.

The pyroelectric coefficient $(\gamma)$ is defined as

$$
\gamma=\frac{d P_{s}}{d T}
$$

where $P_{S}$ is the spontaneous polarization $\left(n C / \mathrm{cm}^{2}\right)$ and $\mathrm{dT}$ is the change in temperature of the sample caused by its heating. In our recent paper ${ }^{9}$, we showed that the pyroelectric properties of FLCs depend not only on the fundamental property given in Eq.(1), but are also strongly dependent on the structure of the material within the cell. Under certain experimental conditions e.g. $d$ (cell thickness) $>>p_{o}$ (pitch of helix) and in the absence of a bias voltage, the sample possesses a helical structure with an average (macroscopic) polarization equal to zero. The application of an electric field leads to distortion of the helix thus producing a non-zero macroscopic polarization $\mathrm{P}_{S}{ }^{*}$. For the case where the director structure is arranged on a helix, the pyroelectric signal I as measured using a lock in amplifier is written ${ }^{9}$ as:

$$
I(f)=K \frac{d P_{S}^{*}}{d T}=K \frac{d P_{S}}{d T} \int_{o}^{P_{o}} \cos \varphi(z, E) d z
$$

Here $K=S d T / d t ; S$ is the electrode area, $d T / d t$ is the rate at which the sample is heated, $\mathrm{p}_{O}$ is the pitch of the helix, $\varphi$ is the azimuthal angle, $\mathrm{z}$ lies along the axis of the helix, $f$ is the chopping frequency of the heat signal. In such a cell, the pyroelectric signal given by I depends not only on $\mathrm{dP}_{S} / \mathrm{dT}$ but also on the structural parameter over one pitch length $\mathrm{p}_{0}$, given by the integral in $\mathrm{Eq}(2)$.

\section{EXPERIMENTAL.}

An automated version of the pyroelectric technique ${ }^{7}$ as devised by Glass et $a^{8}$ to examine the pyroelectric properties of FLC's is used. This technique involves dynamic heating of a FLC cell using a chopped light source at a modulation frequency $f(125 \mathrm{~Hz})$ and subsequent detection of the pyroelectric signal using a lock-in amplifier. The cells consisted of two glass plates $\left(20 \times 14 \mathrm{~mm}^{2}\right)$, coated with a thin layer of Indium Tin 
Oxide (ITO) with an active electrodes region of dimension $8 \times 8 \mathrm{~mm}^{2}$. A polyvinyl alcohol (PVA) coating was spun on the ITO electrodes. Mylar thin-film spacers of $8 \mu \mathrm{m}$ thicknesses are used to achieve the required cell-spacing. The cells are filled in the isotropic phase at $160^{\circ} \mathrm{C}$ and allowed to cool slowly to room temperature. Homogenous alignment of the sample was obtained and this was verified using optical microscopy. The sample was subsequently heated at a rate $0.2^{\circ} \mathrm{C} / \mathrm{min}$.

\section{RESULTS}

Figure 1 shows the spontaneous polarization for different temperatures and applied voltages using the integral current reversal technique ${ }^{10}$. The applied signal is a rectangular wave of frequency $50 \mathrm{~Hz}$.

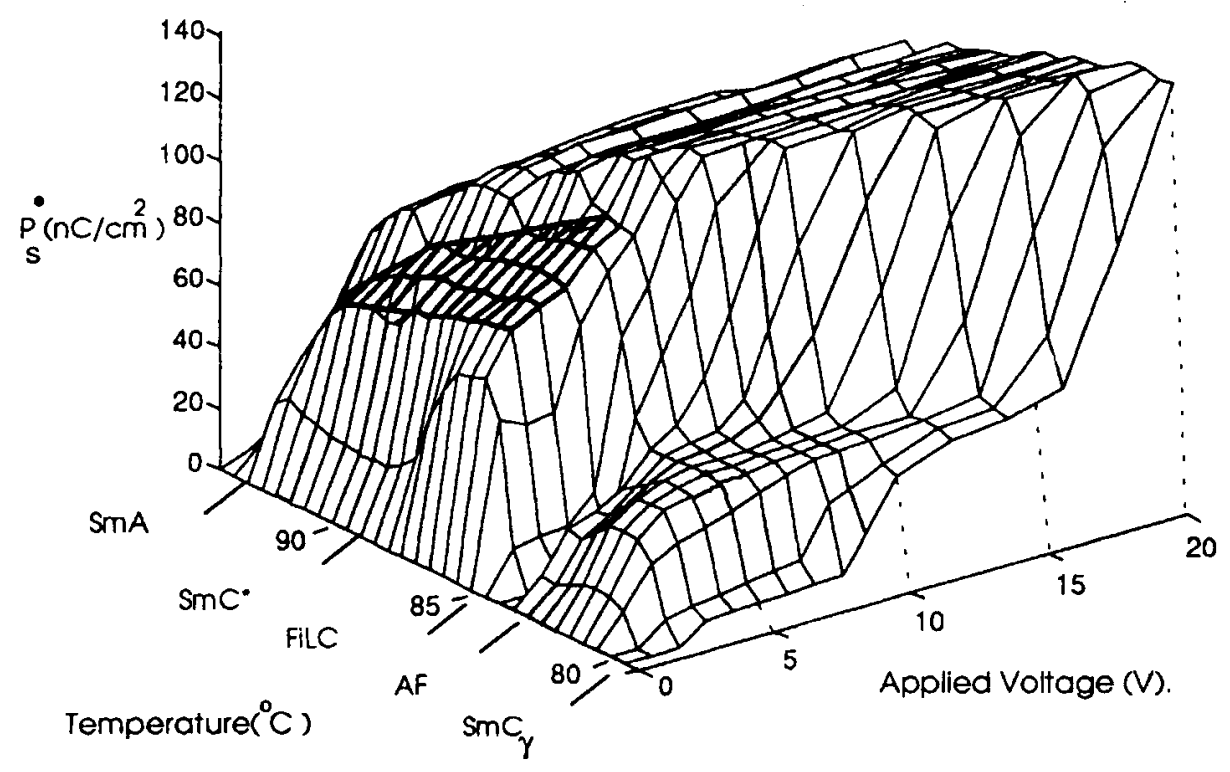

FIGURE 1 Spontaneous polarization $\mathrm{P}_{\mathrm{S}}{ }^{\cdot}\left(\mathrm{nC} / \mathrm{cm}^{2}\right)$ yerses Temperature $\left({ }^{\circ} \mathrm{C}\right)$ and Applied Voltage (V). The region in bold lines is proposed to be a FiLC phase.

The spontaneous polarization is zero in the antiferroelectric $\mathrm{SmC}_{\mathrm{A}}$ phase, and increases on heating to $45 \mathrm{nC} / \mathrm{cm}^{2}$ in the ferrielectric $S m C \gamma$ phase at $\mathrm{T} \geq 78^{\circ} \mathrm{C}$. At $\mathrm{T}=83^{\circ} \mathrm{C}$ a high temperature antiferroelectric phase (AF) is clearly observed. Here the measured spontaneous polarization, $\mathrm{P}_{\mathrm{S}}{ }^{*}$ is 0 . This phase is stable over a temperature interval of $1.5-2^{\circ} \mathrm{C}$ but is destroyed by an applied field $V_{a p p} \geq 5 \mathrm{~V}$. For $V_{a p p}>1 \mathrm{~V}$ an unusual phase 
labelled as FiLC, is observed with $P_{S}^{*}=75 \mathrm{nC} / \mathrm{cm}^{2}$ and this appears to represent a field stabilised high temperature ferrielectric phase. This region is marked with bold lines in Figure 1. This phase is not likely to be a single component phase, it is a mixture of a high temperature ferrielectic phase and a distorted helical $\mathrm{SmC}^{*}$ phase. For an applied voltage, $V_{a p p}>7 V$, the FiLC is not observed and the ferroelectric SmC* phase with $P_{S} *$ $\approx 135 \mathrm{nC} / \mathrm{cm}^{2}$ is found to be stable. This corresponds to an unwound $\mathrm{SmC}^{*}$ phase.

The results given in Fig. 2 show that the pyroelectric signal is strongly dependent on the applied voltage. This is a result of different phases being induced by a varying bias voltage across the sample.

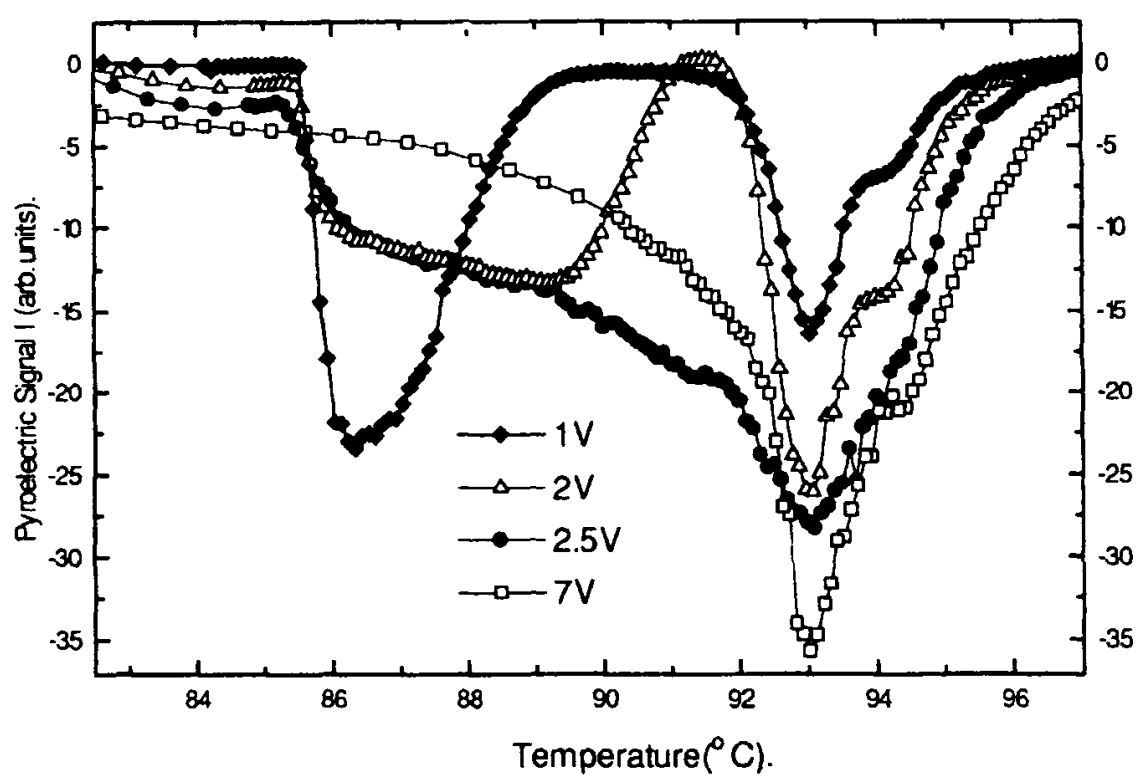

FIGURE 2 The Pyroelectric Signal I (arbitrary units) versus Temperature ( ${ }^{\circ} \mathrm{C}$ ) for bias voltages of $\mathrm{V}=1,2,2.5,7 \mathrm{~V}$. The pyroelectric signal shown for $7 \mathrm{~V}$ is divided by 3 .

For bias voltages of 1 and $2 \mathrm{~V}$, two negative pyroelectric peaks are found. These indicate that the phase transitions $\mathrm{SmA}-\mathrm{SmC}^{*}$ transition occurring at $\mathrm{T}=93^{\circ} \mathrm{C}$ and SmC*-FilC at $\mathrm{T}=87^{\circ} \mathrm{C}$. For bias voltages $\geq 2.5 \mathrm{~V}$ only one pyroelectric peak is observed for the SmA-SmC* transition. 


\section{DISCUSSION}

The dependence of the pyroelectric signal on temperature and bias voltage in the FilC$\mathrm{SmC}^{*}$ phase temperature region shown in Figure 2, is found to be specifically extremely interesting.

For a bias voltage of $1 \mathrm{~V}$, two sharp negative pyroelectric peaks were found. The peak at $\mathrm{T}=93^{\circ} \mathrm{C}$ corresponds to the $\mathrm{SmA}-\mathrm{SmC} \mathrm{C}^{*}$ phase transition and that at $\mathrm{T}=87^{\circ} \mathrm{C}$ is due to the $\mathrm{SmC}^{*}-\mathrm{FiLC}$ transition. In the temperature range $\mathrm{T}=89-92^{\circ} \mathrm{C}$, the pyroelectric signal is close to zero and the pyroelectric coefficient does not change much with temperature. This behaviour indicates that the polarization is almost temperature independent in this region, see Figure 1. On cooling further the pyroelectric signal decreases, a second negative peak at $\mathrm{T}=87^{\circ} \mathrm{C}$ is observed, indicating that the polarization increases sharply. This behaviour is also in agreement with $\mathrm{P}_{\mathrm{S}}{ }^{*}$ measurements. Such an increase in polarization is consistent with the formation of a high temperature ferrielectric phase with $\mathrm{P}_{S}{ }^{*}=3 / 5 \mathrm{P}_{S}$ (Ferro) and $\mathrm{q}_{\mathrm{E}}=4 / 5$, where $\mathrm{P}_{\mathrm{S}}$ (Ferro) corresponds to the spontaneous polarization of the unwound $\mathrm{SmC}^{*}$ phase. The origin of the FiLC phase is most likely to be a phase with $\mathrm{q}_{\mathrm{T}}=3 / 5$ and $\mathrm{P}_{\mathrm{S}}{ }^{*}=1 / 5 \mathrm{P}_{\mathrm{S}}$ (Ferro) and on the application of bias, polarization is higher due to a field induced parameter.

For a bias voltage of $2 \mathrm{~V}$, two negative peaks are also observed. In the $\mathrm{T}=91-92^{\circ} \mathrm{C}$ temperature range the pyroelectric signal is very low and $P_{S}$ does not change much with temperature. A broad pyroelectric transition peak centring at $\mathrm{T}=88^{\circ} \mathrm{C}$, due to the SmC*-FilC phase transition is observed. The pyroelectric peak is broad due to softening of the SmC*-FilC transition. The broad peak is probably due to the coexistence of high temperature FiLC and $\mathrm{SmC}^{*}$ phases. This happens because the nature of the transition between the ferrielectric and ferroelectric phases is effected by the bias voltage. Electric field induced transitions of regions within the ferrielectric phase (FiLC) to $\mathrm{SmC}^{*}$ occur due to interactions of the electric field with the molecular dipoles.

For a bias voltage of $2.5 \mathrm{~V}$, the SmA-SmC* transition is again observed, however the negative pyroelectric peak at $\mathrm{T}=88^{\circ} \mathrm{C}$ disappears and is replaced by a very broad and slowly varying signal. This indicates that the SmC*-FiLC phase transition is not sharp and that FiLC phase has somewhat been transformed to a $\mathrm{SmC}^{*}$ phase.

At a bias voltage of $7 \mathrm{~V}$, the FiLC phase is completely transformed to the field induced $\mathrm{SmC}^{*}$ phase, in agreement with the spontaneous polarization measurements (see Fig. 1). A sharp negative pyroelectric peak at the SmA-SmC* transition indicates that $\mathrm{P}_{\mathrm{S}}^{*}$ increases at the transition SmA-SmC*. This is a typical result for normal ferroelectric liquid crystals. 
At lower temperatures $\left(\mathrm{T}<85^{\circ} \mathrm{C}\right)$ discrepancies between the integrated pyroelectric signal (S) and spontaneous polarization measurements increase. This could be explained by taking into account the results obtained by Ema et $\mathrm{al}^{11}$. They showed that the relaxation time $\left(\tau_{A F}\right)$ between antiferroelectric and ferrielectric phases is of the order of tens of seconds and that the thermal hysteresis between phases is high. The modulation frequency of the heat-signal in our experiment $(\mathrm{dT} / \mathrm{dt})$ is $125 \mathrm{~Hz}$. In this case $\tau_{\mathrm{AF}}$ is greater than the period, $8 \mathrm{~ms}$, of the heat-signal and this leads to inaccuracy in the detection of the antiferroelectric-ferrielectric phase transition by the pyroelectric technique.

\section{CONCLUSIONS}

A strong dependence of the pyroelectric signal on temperature and bias has been reported. The existence of a high temperature FiLC phase, with $\mathrm{q}_{\mathrm{T}}=3 / 5$, is found from the pyroelectric measurements. The stability of this phase is found to be dependent on temperature and bias voltage. It is found that for a sufficiently large bias voltage this phase is transformed to a SmC* phase. At temperatures below those of $\mathrm{AF}-\mathrm{SmC}$ phase transition, discrepancies between the pyroelectric and polarization measurements occur. The main reasons for these discrepancies are the large relaxation times of the antiferroferrielectric phases.

\section{BEFERENCES}

1. E. Gorecka, A. D. L. Chandani, Y. Ouchi, H. Takezoe and A. Fukuda. Jap. L Appl, Phys., 29, 131 (1990).

2. Y. Galeme and L. Liebert. Phys.Rev.Letl., 66, 2891 (1991).

3. A. Fukuda, Y. Takanishi, T. Isozaki, K. Ishikawa and H. Takezoe. J Mater. Chem. 4, 997 (1994).

4. J. W. Goodby, J. S. Patel and E. Chin. L, Mater. Chem., 2, 197 (1992).

5. I. Nishiyama and J. W. Goodby. L.Mater. Chem., 2, 1015 (1992).

6. Y. Yamada, N. Yamamoto, K. Mori, K. Nakamura, T. Hagiwari, Y. Suzuki, I. Kawamura, H. Orihara and Y. Ishibashi. Jpn. J. Appl. Phys., 29, 1757 (1990).

7. A. Kocot, R. Wrzalik, J. K. Vij and R. Zentel, J. Appl, Phys., 75, 728 (1994).

8. A. M.Glass, J. S. Patel, J. W. Goodby and D. H. Olson. J. Appl. Phys., 60, 2778 (1986).

9. J. W. O' Sullivan, Yu. P. Panarin and J. K. Vij. J. Appl. Phys., 7Z, 1201 (1995).

10. V. M. Vaksman and Yu. P.Panarin. Mol, Mat., 1, 147 (1992).

11. K. Ema, H. Yao, I. Kawamura, T. Chan and C. W. Garland. Phys, Rev, E., 47, 1203 (1993).

12. Yu. P. Panarin, H. Xu, S. T. MacLughadha, J. K. Vij, A. J. Seed, M. Hird and J.W. Goodby. J. Phys. : Condensed Matter., Z, L351 (1995). 